NISTIR 7456

\title{
Effect of Lubricant on R410A Horizontal Flow Boiling
}

Nitin N. Sawant Mark A. Kedzierski

J. Steven Brown 
NISTIR 7456

\title{
Effect of Lubricant on R410A Horizontal Flow Boiling
}

\author{
Nitin N. Sawant \\ Mark A. Kedzierski \\ J. Steven Brown \\ U.S DEPARTMENT OF COMMERCE \\ National Institute of Standard and Technology \\ Building Environment Division \\ Building and Fire Research Laboratory \\ Gaithersburg, MD 20899-8631
}

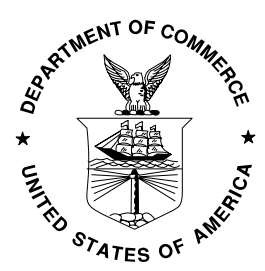

U.S. Department of Commerce Carlos M. Gutierrez, Secretary 


\title{
Effect of Lubricant on R410A Horizontal Flow Boiling
}

\author{
N. N. Sawant \\ The Catholic University of America \\ Washington, DC 20064 \\ M. A. Kedzierski \\ National Institute of Standards and Technology \\ Gaithersburg, MD 20899 \\ J. S. Brown \\ The Catholic University of America \\ Washington, DC 20064
}

\begin{abstract}
This paper experimentally determines the effect of lubricant on R410A horizontal flow boiling. A baseline was established by measuring the convective boiling heat transfer performance of pure R410A. In addition, the heat transfer performance of an R410A/lubricant (99.6/0.4) mixture was measured and compared to that of the lubricantfree refrigerant. The measured convective boiling Nusselt numbers for the lubricant-free R410A and R410A/lubricant mixture were compared to an existing correlation. The correlation was shown to predict $71 \%$ and $83 \%$ of the lubricant-free R410A and the R410A/lubricant Nusselt numbers to within $\pm 20 \%$, respectively. The mean degradation in the heat transfer performance with the addition of lubricant was approximately $6.7 \%$. A measurement technique for observing the fluorescence of the lubricant in the annular flow was developed. Further improvements in the technique are necessary before it can be used to visualize the distribution of lubricant within the flow.
\end{abstract}

Keywords: Flow boiling, micro-fin, R410A, refrigerant/lubricant mixture 


\section{TABLE OF CONTENTS}

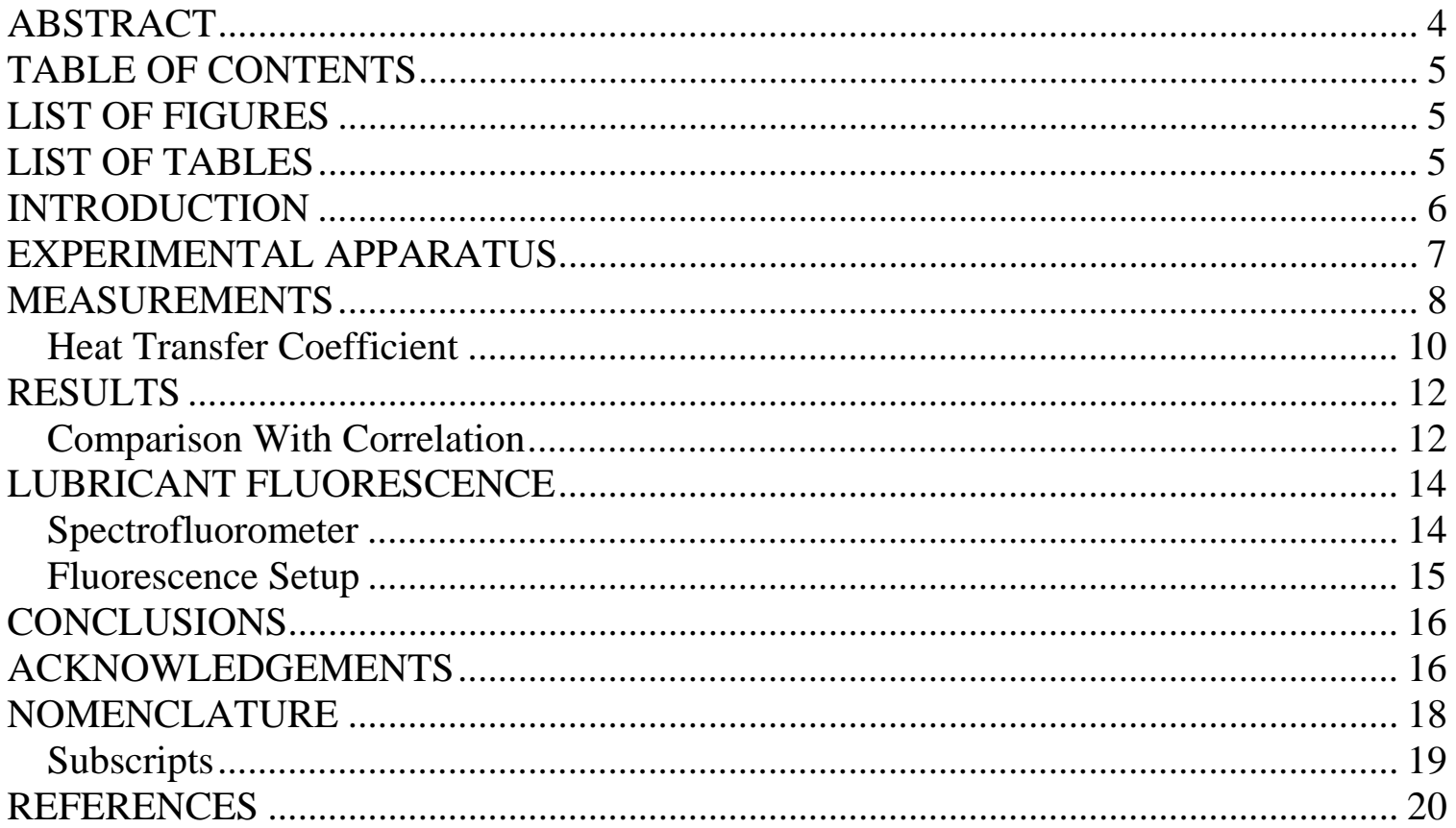

\section{LIST OF FIGURES}

Fig. 1 Schematic of test rig .................................................................................... 24

Fig. 2 Cross section of test section......................................................................... 25

Fig. 3 Test section detail ..................................................................................... 26

Fig. 4 Comparison of measurements with REFPROP 7.1 (2006) ……........................... 27

Fig. 5 Difference between oil-free R410A and R410A/POE saturated liquid equilibrium

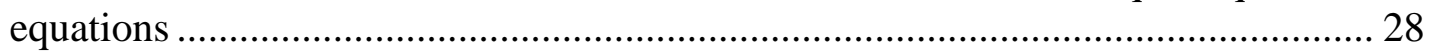

Fig. 6 Heat flux distribution for pure R410A and R410A/POE mixture ........................ 29

Fig. 7 Comparison of the heat transfer coefficient for pure R410A and R410A/POE

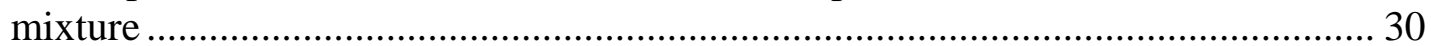

Fig. 8 Comparison of counterflow data with existing correlation ..................................... 31

Fig. 9 Apparent heat transfer degradation due to oil ............................................... 32

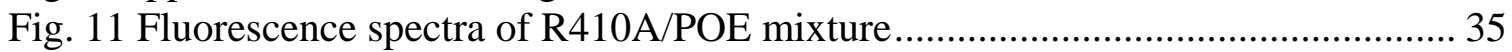

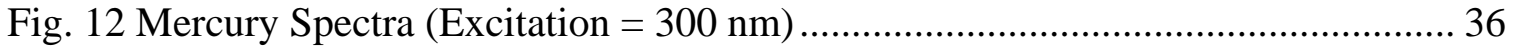

Fig. 13 Lubricant concentration observation test section ................................................ 37

\section{LIST OF TABLES}

Table 1 Median estimated $95 \%$ relative expanded uncertainties for measurements...22

Table 2 Calibration check of spectrofluorometer against Mercury lamp......................23 


\section{INTRODUCTION}

Many new evaporators and condensers in the residential air-conditioning industry employ enhanced micro-fin tubes rather than smooth tubes. In fact, the micro-fin tube dominates unitary equipment design because it provides the highest heat transfer with the lowest pressure drop among the commercially available internal enhancements (Webb, 1994). Because of the recent changeover to the production of environmentally friendlier refrigerants without ozone depleting chlorine, R410A has received significant interest from researchers. For example, Kim and Shin (2005) compared fluid-heated flow boiling heat transfer performance of R22 to that of R410A in smooth and micro-fin tubes. They investigated the heat transfer coefficient for the micro-fin tubes as a function of refrigerant quality. When compared to R22 at the same test conditions, the evaporating heat transfer coefficients for R410A were $97 \%$ to $129 \%$ of R22.

Because most compressors are lubricated, the effect of lubricant on the boiling heat transfer coefficient of refrigerants has been extensively studied. For example, Cremaschi et al. (2005) conducted measurements on oil retention characteristics in the condenser, evaporator, liquid and suction lines of air-conditioning systems employing refrigerants R22, R134a, and R410A along with miscible and non-miscible lubricants. The oil retention was shown to depend on several parameters such as oil mass fraction, vapor refrigerant mass flux, mixture viscosity ratio, and orientation of the pipe. At an oil mass fraction of $5 \%$, the poorly miscible and soluble R410A/Mineral Oil combination retained oil in the suction line by approximately $31 \%$ more by mass than that of the miscible R410A/Polyolester Oil combination. In addition, Lottin et al. (2003) used a theoretical model to explain the effect synthetic oil would have on the performance of a R410A compression refrigeration system. In the evaporator, optimum performance was observed with a $0.1 \%$ oil mass fraction. The motivation for this study is the fact that there is no significant documentation of the effect of lubricant on the convective boiling heat transfer of R410A.

More measurements of local evaporation heat transfer are needed by the refrigeration industry for accurate sizing of micro-fin tube evaporators. One of the objectives of this study, therefore, is to provide a source of information for the boiling of R410A with and without the addition of a polyolester (POE) lubricant. A second purpose is to visually investigate horizontal nucleate flow boiling characteristics of R410A with a high-speed camera. A further motivation for this study is to describe the development of a fluorescence measurement technique to explore the influence of heat flux on the lubricant surface density. A mixture of napthenic mineral oil and POE lubricant (1 \% and $99 \%$ by mass, respectively) was chosen for its favorable fluorescence characteristics and to demonstrate a new measurement technique. The POE employed in this study had a nominal kinematic viscosity of $68 \mu \mathrm{m}^{2} / \mathrm{s}$ at $297.8 \mathrm{~K}$. 


\section{EXPERIMENTAL APPARATUS}

The evaporative heat transfer of R410A was studied in a concentric tube-in-tube heat transfer test apparatus. A schematic of the test apparatus is shown in Fig. 1. The test setup consisted of an evaporator (test section), condenser, subcooler, preheater, and magnetic gear pump. A magnetically coupled gear pump delivered R410A to the entrance of the test section in a subcooled state. Another magnetically coupled gear pump supplied a steady flow of distilled water to the annulus of the test section.

The refrigerant flow rate and pressure were fixed at the inlet to the test section. Redundant refrigerant-side flow rate measurements were made with a Coriolis flowmeter and a turbine flowmeter. The inlet water temperature was held constant for each test with a water-chilled heat exchanger and variable electric heaters. The fixed water flow rate and the inlet water temperature were used to establish the overall refrigerant quality change in the test section. The water temperature change, the tube wall temperature, the refrigerant temperatures, pressures, and pressure drops were measured at several axial locations along the test section. These measurements were used to calculate the local heat-transfer coefficient for the micro-fin tube.

The test section consisted of a pair of $3.34 \mathrm{~m}$ long, horizontal tubes connected by a Ubend. A fixed test pressure was maintained by balancing the refrigerant duty between the subcooler, the test section, and the evaporator. Figure 2 shows a cross section of the test section with a detail of the micro-fin tube geometry. In the test section, the refrigerant flowed inside a micro-fin tube, while distilled water flowed either in counterflow or in parallel flow to the refrigerant in the annulus that surrounded the micro-fin tube. The annulus gap was $2.2 \mathrm{~mm}$, and the micro-fin tube wall thickness was $0.3 \mathrm{~mm}$. The microfin tube has $60,0.2 \mathrm{~mm}$ high fins with an $18^{\circ}$ helix angle. For this geometry, the cross sectional flow area was $60.8 \mathrm{~mm}^{2}$ giving an equivalent smooth diameter $\left(D_{e}\right)$ of $8.8 \mathrm{~mm}$. The root diameter of the micro-fin tube was $8.91 \mathrm{~mm}$. The inside-surface area per unit length of the tube was estimated to be $44.6 \mathrm{~mm}$. The hydraulic diameter $\left(D_{h}\right)$ of the micro-fin tube was estimated to be $5.45 \mathrm{~mm}$. The ratio of the inner surface area of the micro-fin tube to the surface area of a smooth tube of the same $D_{e}$ was 1.6. The fins rifled down the axis of the tube at a helix angle of $18^{\circ}$ with respect to the tube axis.

Figure 3 provides a detailed description of the test section. The annulus was constructed by connecting a series of tubes with 14 pairs of stainless steel flanges. This construction permitted the measurement of both the outer micro-fin wall temperature and the water temperature change as discussed in the following two paragraphs. The design also avoided abrupt discontinuities such as unheated portions of the test section and tube-wall "fins" between thermopile ends.

Figure 3 shows that thermocouple wires (labeled LT) pass between 12 of the gasketed flange pairs to measure the refrigerant-tube wall temperature at ten locations on the top, side, and bottom of the tube wall. These locations were separated by $0.6 \mathrm{~m}$ on average, and they were located near the intersection of the shell flanges. In addition to these, thermocouples were also mounted next to the pressure taps near the middle of each test section length. The thermocouple junction was soldered to the outside surface and was 
sanded to a thickness of $0.5 \mathrm{~mm}$. The leads were strapped to a thin non-electricallyconducting epoxy layer on the wall for a distance of $14.3 \mathrm{~mm}$ before they passed between a pair of the shell flanges. The wall temperature was corrected for a heat-flux dependent fin effect. The correction was typically $0.05 \mathrm{~K}$. Figure 3 also shows that a chain of thermopiles was used to measure the water temperature change between each flange location. Each thermopile consisted of 10 thermocouples in series, with ten junctions at each end evenly spaced around the circumference of the annulus. Because the upstream junctions of one thermopile and the downstream junctions of another tend to enter the annulus at the same axial location (except at the water inlet and outlet), the junctions of the adjacent piles were alternated around the circumference. A series of Teflon ${ }^{1}$ half rings attached to the inner refrigerant tube centered the tube in the annulus. The halfrings were circumferentially baffled to mix the water flow. Mixing was further ensured by a high water Reynolds number (Kattan et al., 1995).

As shown in Fig. 3, six refrigerant pressure taps (labeled P) along the test section allowed the measurement of the upstream absolute pressure and five pressure drops along the test section. Two sets of two water pressure taps were used to measure the water pressure drop along each tube. Also, a sheathed thermocouple measured the refrigerant temperature at each end of the two refrigerant tubes, with the junction of each centered radially. Only the thermocouple at the inlet of the first tube was used in the calculations. The entire test section was wrapped with $5 \mathrm{~cm}$ of foam insulation to minimize heat transfer between the water and the ambient.

\section{MEASUREMENTS}

The system was charged with a commercially available R410A. Its composition was maintained by thorough evacuation of the test rig before charging and only charging liquid from the commercial cylinder.

Flow boiling heat transfer measurements were obtained for three different average refrigerant pressures of $1.034 \mathrm{MPa}, 1.068 \mathrm{MPa}$, and $1.103 \mathrm{MPa}$. The refrigerant mass flow rate was varied to achieve mass fluxes in the range from $100 \mathrm{~kg} / \mathrm{m}^{2} \mathrm{~s}$ to $400 \mathrm{~kg} / \mathrm{m}^{2} \mathrm{~s}$. The average refrigerant saturation temperature, $T_{\mathrm{r}}$, was varied between $7.2{ }^{\circ} \mathrm{C}$ and $10{ }^{\circ} \mathrm{C}$ with approximately $1 \mathrm{~K}$ subcooling at the test section inlet.

A data acquisition system and a tailored software program were used to record all the conditions in a data file. All saturated refrigerant properties, with the exception of the equilibrium mixture temperature, were evaluated at the measured saturation pressure using version 7.1 of REFPROP (Lemmon et al., 2006) mixture property routines.

\footnotetext{
${ }^{1}$ Certain trade names and company products are mentioned in the text or identified in an illustration in order to adequately specify the experimental procedure and equipment used. In no case does such an identification imply recommendation or endorsement by the National Institute of Standards and Technology, nor does it imply that the products are necessarily the best available for the purpose.
} 


\section{Equilibrium Refrigerant Temperature}

Considering that the test fluid was a commercially prepared mixture, the pressure and the temperature characteristics could vary with composition and purity. Depending on the manufacturing process, stray components such as R115 may be present in the mixture causing a deviation from the "standard" or desired mixture properties of R410A. For example, the measured saturation temperature of the R410A test fluid used in this study differed from that obtained from REFPROP 7.1 by approximately $1 \mathrm{~K}$ for the pressure range tested. To alleviate this discrepancy, vapor equilibrium measurements were made for the test fluid of this study for temperatures between $280 \mathrm{~K}$ and $300 \mathrm{~K}$ and pressures between 1.0 MPa and 1.2 MPa.

A precisely controlled temperature liquid bath was used with a glass standard platinum resistance thermometer calibrated to within $\pm 0.005 \mathrm{~K}$. A constant volume vessel instrumented with a pressure transducer with an uncertainty of $\pm 0.01 \mathrm{kPa}$ was charged with the test fluid and fully immersed in the bath. The mass quality of the charge was calculated from the known volume and the charged mass. The densities of the vapor and the liquid were obtained from version 7.1 of REFPROP (Lemmon et al., 2006) at the measured temperature. The saturation temperature $\left(T_{\mathrm{r}}\right)$, refrigerant pressure $\left(P_{\mathrm{r}}\right)$ and thermodynamic mass quality $\left(x_{q}\right)$ were correlated for R410A without lubricant as:

$$
\frac{1}{T_{\mathrm{r}}}=A_{0}+A_{1} \ln \left(P_{\mathrm{r}}\right)+A_{2} x_{q}
$$

where $T_{\mathrm{r}}$ is in $\mathrm{K}$ and $P_{\mathrm{r}}$ is given in $\mathrm{kPa}$. The constants are $A_{0}=0.658452 \times 10^{-2} \mathrm{~K}^{-1} ; A_{1}=$ $0.434741 \times 10^{-3} \mathrm{~K}^{-1} ; A_{2}=-0.129204 \times 10^{-5} \mathrm{~K}^{-1}$ with the temperature residuals being between $-0.005 \mathrm{~K}$ and $0.01 \mathrm{~K}$.

Figure 4 shows that eq. (1) represents the measured temperature to within $\pm 0.01 \mathrm{~K}$ for pressures between $1 \mathrm{MPa}$ and 1.2 MPa. Equation 1, the locally measured pressure, and the calculated thermodynamic quality were used to calculate the saturated temperature for all of the measurements reported in this study.

The constants in eq. (1) were modified to predict the saturated conditions of R410Allubricant mixtures following the procedure given by Thome (1995):

$$
\frac{1}{T_{\mathrm{r}}}=\frac{\ln \left(P_{\mathrm{r}}\right)-b+\frac{A_{2}}{A_{1}} X_{q}}{a}
$$

The $a$ and $b$ are fourth degree polynomials in the local lubricant mass fraction in the refrigerant liquid $\left(w_{1}\right)$ :

$$
\begin{aligned}
& a=-2300.2 \mathrm{~K}+182.5 \mathrm{~K} w_{1}-724.2 \mathrm{~K} w_{1}^{2}+3868.0 \mathrm{~K} w_{1}^{3}-5268.9 \mathrm{~K} w_{1}^{4} \\
& b=15.146-0.722 w_{1}+2.391 w_{1}^{2}-13.779 w_{1}^{3}+17.066 w_{1}^{4}
\end{aligned}
$$


where the local lubricant mass fraction was obtained from the quality and the all-liquid $\left(x_{\mathrm{q}}=0\right)$ lubricant mass fraction $\left(w_{\mathrm{b}}\right)$ as:

$$
w_{1}=\frac{1}{\frac{1-x_{q}}{w_{\mathrm{b}}}-1}
$$

All of the coefficients of the $a$ and $b$ polynomials with the exception of the constant terms were taken from Thome (1995). The constant terms of the polynomials were adjusted to reproduce the oil-free R410A expression given in eq. (1) when $w_{1}=0$.

Figure 5 illustrates the magnitude of the effect that $0.4 \%$ mass fraction of lubricant has on the saturation temperature of R410A for a saturation pressure of $1100 \mathrm{kPa}$ and various qualities. In general, the lubricant increases the saturation temperature by less than $0.025 \mathrm{~K}$ for qualities less than 0.5 .

\section{Heat Transfer Coefficient}

Table 1 shows the expanded measurement uncertainty $(U)$ of the various measurements along with the range of each parameter in this study. The $U$ was estimated with the law of propagation of uncertainty. All expanded measurement uncertainties are reported at the $95 \%$ confidence level. The estimates shown in Table 1 are median values of $U$ for the correlated data.

The convective boiling heat transfer coefficient based on the actual inner surface area $\left(h_{2 \Phi}\right)$ was calculated as:

$$
h_{2 \Phi}=\frac{q "}{T_{w}-T_{r}}
$$

where the measured wall temperatures $\left(T_{\mathrm{w}}\right)$ were fitted to their axial positions to reduce the uncertainty in the measurement. The measured wall temperatures were fitted to:

$$
T_{\mathrm{w}}=A_{0}+A_{1} z+A_{2} z^{2}
$$

The water temperature $\left(T_{\mathrm{f}}\right)$ was determined from the measured temperature change obtained from each thermopile and the inlet water temperature measurement. The water temperature was regressed to the axial location of the thermopiles along the z-coordinate (see Fig. 3). The water temperatures were fitted to:

$$
T_{\mathrm{f}}=B_{0}+B_{1} z+B_{2} z^{2}+B_{3} z^{3}
$$


The water temperature fits, the measured water mass flow rate $\left(\dot{m}_{\mathrm{f}}\right)$, and the properties of the water were used to calculate the local heat flux ( $q$ ”) to the micro-fin tube based on the actual inner surface area:

$$
q^{\prime \prime}=\frac{\dot{m}_{f}}{p}\left(c_{p_{f}} \frac{\mathrm{d} T_{f}}{\mathrm{~d} z}+v_{f} \frac{\mathrm{d} P_{f}}{\mathrm{~d} z}\right)
$$

where $p$ is the wetted perimeter of the inside of the micro-fin tube. The specific heat $\left(c_{\mathrm{pf}}\right)$ and the specific volume $\left(v_{\mathrm{f}}\right)$ of the water were calculated locally as a function of the water temperature. The local axial water temperature gradient $\left(\mathrm{d} T_{\mathrm{f}} / \mathrm{d} z\right)$ was calculated from the derivative of eq. (7). The water pressure gradient $\left(\mathrm{d} P_{\mathrm{f}} / \mathrm{d} z\right)$ was linearly interpolated between the pressure taps to the location of the wall thermocouples. The pressure gradient term was typically less than $3 \%$ of the temperature gradient term.

Figure 6 shows an example of the local heat flux for lubricant-free R410A and the R410/lubricant mixture as calculated from eq. (8) versus thermodynamic quality for counterflow and a fixed exit test section pressure of 1.1 MPa. For a given quality, the heat flux for the lubricant-free $\mathrm{R} 410 \mathrm{~A}$ is roughly $3 \mathrm{~kW} / \mathrm{m}^{2}$ larger than that of the R410A/POE (99.6/0.4) mixture, but has approximately the same nearly constant rate of increase with respect to quality.

The enthalpy of the refrigerant at the inlet of the test section was calculated from its equilibrium refrigerant temperature and measured pressure. The subsequent change in the refrigerant enthalpy along the test section was calculated from the local heat flux and the measured refrigerant mass flow rate. The refrigerant pressures were measured at six pressure taps along the test section. The pressure was linearly interpolated between the taps. The test refrigerant entered the test section nearly as saturated liquid having approximately $1 \mathrm{~K}$ of subcooling. The average saturation temperature, $T_{\mathrm{r}}$, at the inlet varied between $7.2{ }^{\circ} \mathrm{C}$ and $10{ }^{\circ} \mathrm{C}$.

The local Nusselt number $(\mathrm{Nu})$ was calculated using the hydraulic diameter $\left(D_{\mathrm{h}}\right)$ and the heat transfer coefficient based on the actual inner surface area of the tube $\left(h_{2 \Phi}\right)$ as:

$$
\mathrm{Nu}=\frac{h_{2 \phi} D_{\mathrm{h}}}{k_{\mathrm{l}}}
$$

where $k_{\mathrm{l}}$ is the thermal conductivity of the liquid.

The hydraulic diameter was measured with a polar planimeter from a scaled drawing of the tube cross section, but it can be approximated for other tube geometries with fin parameters by expanding on the expression that was given for $D_{\mathrm{h}}$ in Kedzierski and Goncalves (1999): 


$$
D_{\mathrm{h}}=\frac{4 A_{\mathrm{c}} \cos \alpha}{N_{\mathrm{f}} S}=\frac{\left(\pi D_{\mathrm{r}}^{2}-2 N_{\mathrm{f}} t_{\mathrm{b}} e\right) \cos \alpha}{s+\frac{2 e}{\cos (\beta / 2)}}
$$

Figure 2 shows the fin parameters that are used in eq. (10) where $S$ is the perimeter of one fin and channel taken perpendicular to the axis of the fin, $s$ is the spacing between the fins, $\beta$ is the fin-tip angle, $e$ is the fin height, $\alpha$ is the twist angle of the fins, $t_{b}$ is the thickness of the fin at its base, $N_{f}$ is the total number of fins, and $D_{r}$ is the diameter of the tube at the fin root, i.e., fin base. The hydraulic diameter of the present tube geometry of this study as estimated from eq. (10) is $5.2 \mathrm{~mm}$, while that obtained from the planimeter and used in the data reduction was $5.45 \mathrm{~mm}$.

The internal surface area of the fin per unit length $\left(A_{\mathrm{i}} / L\right)$ can be estimated from:

$$
\frac{A_{1}}{L}=N_{\mathrm{f}}\left(\frac{s}{\cos \alpha}+\frac{2 e}{\cos \alpha \cos (\beta / 2)}\right)
$$

The $A_{\mathrm{i}} / L$ estimated from eq. (11) is $46.8 \mathrm{~mm}$, while that obtained from the planimeter and used in the data reduction was $44.6 \mathrm{~mm}$.

Figure 7 shows a comparison of the R410A heat transfer coefficient versus quality to that for the R410A/POE (99.6/0.4) mixture for a mass flux of approximately $200 \mathrm{~kg} / \mathrm{m}^{2}$. In general, the measured boiling heat transfer coefficients are nearly constant with respect to quality over the range tested. Thinning of the liquid film on the wall for larger qualities is expected to induce an increase in the heat transfer coefficient. It is speculated that the actual heat transfer increase is not evident because the increase is within the uncertainty of the heat transfer measurement. On average, the refrigerant/lubricant mixture heat transfer coefficient is approximately $300 \mathrm{Wm}^{-2} \mathrm{~K}^{-1}$ less than the pure $\mathrm{R} 410 \mathrm{~A}$ heat transfer coefficient, which represents approximately a $6 \%$ degradation in the heat transfer due to the lubricant for these particular conditions.

\section{DISCUSSION}

Comparison With Correlation

Hamilton et al. (2005) correlated micro-fin-tube-convective boiling Nusselt numbers for four pure refrigerants: R22, R32, R125, and R134a; and four refrigerant mixtures: R410B (R32/R125, $45 \% / 55 \%$ mass), R32/R134a (27 \%/73 \% and $30 \% / 70 \%$ mass) and R407C (R32/R125/R134a, $25 \% / 23 \% / 52 \%$ mass) to a single expression consisting of a product of dimensionless properties:

$$
\mathrm{Nu}=482.18 \mathrm{Re}^{0.3} \operatorname{Pr}^{\mathrm{C}_{1}}\left(\frac{P_{\mathrm{r}}}{P_{\mathrm{c}}}\right)^{\mathrm{C}_{2}} \mathrm{Bo}^{\mathrm{C}_{3}}\left(-\log _{10} \frac{P_{\mathrm{r}}}{P_{\mathrm{c}}}\right)^{\mathrm{C}_{4}} M_{\mathrm{r}}^{\mathrm{C}_{5}} 1.1^{\mathrm{C}_{6}}
$$

where

$C_{1}=0.51 x_{\mathrm{q}}$

$C_{2}=5.57 x_{\mathrm{q}}-5.21 x_{\mathrm{q}}^{2}$ 
$C_{3}=0.54-1.56 x_{\mathrm{q}}+1.42 x_{\mathrm{q}}^{2}$

$C_{4}=-0.81+12.56 x_{\mathrm{q}}-11.00 x_{\mathrm{q}}^{2}$

$C_{5}=0.25-0.035 x_{\mathrm{q}}^{2}$

$C_{6}=1 / \mathrm{T}_{\mathrm{s}}\left(\left(\mathrm{T}_{\mathrm{LV}}-\mathrm{T}_{\mathrm{MV}}\right)\left\{279.8\left(x_{\mathrm{v}}-x_{\mathrm{l}}\right)-4298\left(\mathrm{~T}_{\mathrm{d}}-\mathrm{T}_{\mathrm{b}}\right) / \mathrm{T}_{\mathrm{s}}\right\}\right)$

The limits of applicability for the correlation are:

$70 \mathrm{~kg} / \mathrm{m}^{2} \mathrm{~s}<\mathrm{G}_{\mathrm{r}}<370 \mathrm{~kg} / \mathrm{m}^{2} \mathrm{~s} \quad$ and $\quad 0<x_{\mathrm{q}}<0.7$

The correlation was shown by Hamilton et al. (2005) to predict some of the existing data from the literature to within $\pm 20 \%$. Cooper (1984) suggested that the fluid properties that govern nucleate pool boiling can be well represented by a product of the reduced pressure $\left(P_{r} / P_{c}\right)$, the acentric factor $\left(-\log _{10}\left(P_{r} / P_{c}\right)\right)$, and other dimensionless variables to various powers. The all-liquid Reynolds number $(\mathrm{Re})$, the Boiling number $(\mathrm{Bo})$, the liquid Prandtl number $(\mathrm{Pr})$, the reduced pressure $\left(P_{\mathrm{r}} / P_{\mathrm{c}}\right)$, and the quality $\left(x_{\mathrm{q}}\right)$ were all evaluated locally at the saturation temperature. $M_{\mathrm{r}}$ is the molar mass of the refrigerant in $\mathrm{g} / \mathrm{mol}$.

The all-liquid Reynolds number and the Nusselt number are based on the hydraulic diameter. Also, the Nusselt number is based on the actual inner surface area of the tube. The $T_{\mathrm{d}}$ and $T_{\mathrm{b}}$ are the dew point temperature and the bubble point temperature of the mixture, respectively, evaluated at the local saturation pressure and overall composition. The $T_{\mathrm{LV}}$ and the $T_{\mathrm{MV}}$ are the saturation temperatures of the least volatile (pure) component and the most volatile component, respectively, evaluated at the saturation pressure of the mixture. The mass fraction of the vapor $\left(x_{\mathrm{v}}\right)$ and that of the liquid $\left(x_{1}\right)$ are evaluated at the saturation pressure and the local thermodynamic quality, while the overall composition is the all-liquid or all-vapor value. The constant $C_{6}$ is zero for pure refrigerants and was approximately 0.15 for much of the R410A data.

Figure 8 provides a comparison of the Nusselt numbers predicted with eq. (12) for the micro-fin tube to those measured in this study for lubricant-free R410A and the R410A/POE mixture. Approximately $71 \%$ of the measured, lubricant-free, data fall within $\pm 20 \%$ of the predicted data. The lubricant-free measurements that were outside the $\pm 20 \%$ region of the predicted data were for conditions that were very close to those of the measurements that were well predicted. No justifiable reason was found to identify these points as outliers. Figure 8 also shows that eq. (12) predicts $83 \%$ of the R410A/POE Nusselt numbers to within $\pm 20 \%$. The R410A/POE predictions were made using the R410A/POE mixture liquid viscosity and liquid density evaluated at the local lubricant mass fraction to calculate the Re and $\mathrm{Pr}$ in eq. (12). Use of the lubricant properties in the correlation caused between a $0.3 \%$ and a $0.8 \%$ reduction in the Nusselt number as compared to results using the lubricant-free R410A properties alone.

Figure 9 shows the heat transfer degradation due to the lubricant $\left(\Delta \mathrm{Nu}_{\mathrm{d}}\right)$ as a function of the thermodynamic quality for all of the measured R410A/POE data. The $\Delta \mathrm{Nu}_{\mathrm{d}}$ was calculated from the following definition: 


$$
\Delta \mathrm{Nu}_{\mathrm{d}}=100\left(\mathrm{Nu}_{\mathrm{p}}-\mathrm{Nu}_{\mathrm{m}}\right) / \mathrm{Nu}_{\mathrm{p}}
$$

where $\mathrm{Nu}_{\mathrm{p}}$ is the Nusselt number obtained from the lubricant-free correlation (eq. (12)) using the lubricant-free R410A properties, while $\mathrm{Nu}_{\mathrm{m}}$ is the Nusselt number obtained from the measured refrigerant/lubricant mixture heat transfer data. The figure shows that the degradation in heat transfer due to the addition of $0.4 \%$ mass fraction is between $-20 \%$ and $+42 \%$ exhibiting no apparent relationship with respect to quality. The average degradation due to the presence of the lubricant was approximately $6.7 \%$, which is within the uncertainty of both the measurements and the predictions.

\section{LUBRICANT FLUORESCENCE}

Several measurement techniques exist to measure the bulk lubricant concentration in a refrigerant (Navarro de Andrade et al., 1999). These techniques rely on the measurement of various properties of the lubricant: density, light absorption, viscosity, and speed of sound. For example, Navarro de Andrade et al. (1999), Meyer and Saiz Jabardo (1994), and Baustian et al. (1988a) used temperature and speed of sound measurements of a liquid refrigerant/lubricant mixture to determine the bulk concentration of the mixture. Baustian et al. (1988b) used a bypass viscometer to correlate the mixture viscosity to the flowing lubricant concentration. Suzuki et al. (1993) used the light absorption properties of lubricant to quantify the fraction of lubricant in the refrigerant. Finally, Baustian et al. (1988c) and Bayani et al. (1995) demonstrated the use of a flowmeter densimeter to measure the concentration of lubricant in the liquid line of a refrigeration system. All of these methods are more suited for the measurement of the bulk lubricant concentration of a non-boiling fluid rather than of the localized lubricant distribution in a two-phase annular flow, which cannot be measured using a global measurement technique.

With the purpose of confirming the existence of the lubricant excess layer on a boiling heat transfer surface, Kedzierski et al. (1998) proposed an in-situ measurement technique that relied on the fluorescent properties of the lubricant. The proposed method made use of the relative fluorescent properties of the lubricant and the refrigerant. Ideally, the lubricant should strongly fluoresce while the refrigerant should not fluoresce. In this way, the amount of lubricant in the mixture can be calculated from the intensity of the fluorescence emission. Kedzierski et al. (1998) demonstrated that the fluorescence intensity of a lubricant/methanol film on an adiabatic surface could be measured and that the intensity of the fluorescence increased with lubricant concentration. The present study has developed a method for exciting the lubricant in the annular flow so that its location can be documented and studied in order to contribute data for the modeling of refrigerant/lubricant flow boiling.

\section{Spectrofluorometer}

Figure 10 shows a simplified schematic of the right angle spectrofluorometer consisting of a xenon light source, an excitation and an emission monochromator, and an emission photomultiplier tube (detector). The light source was focused into the excitation monochromator by a collimating lens. The monochromator was set to emit light at a wavelength of $320 \mathrm{~nm}$. Because the intensity of the xenon lamp varies with wavelength, a corrected excitation module was used to compensate for the variation. The light from 
the excitation monochromator passed through a $2.5 \mathrm{~nm}$ slit before it entered the sample chamber. All of the slit widths were $2.5 \mathrm{~nm}$ to limit the bandwidth of the wavelength. The spectrofluorometer was designed to accept $45 \mathrm{~mm}$ x $10 \mathrm{~mm}$ x $10 \mathrm{~mm}$ fluorescent samples or cuvettes filled with fluorescent material. The emission monochromator was used to select the optimum wavelength to measure the fluorescent intensity. The intensity of the emission was measured with a photomultiplier tube and accompanying electronics.

Preliminary tests with the pure POE lubricant in a cuvette showed that the fluorescence intensity of the lubricant was not sufficient for measurement in the test rig. Consequently, the POE lubricant was mixed with a mineral oil (MO) that was known to have a strong fluorescent intensity. Several mixtures of the MO and the POE (MO/POE ( $20 \% / 80 \%$ by mass), MO/POE (10\%/90 \% by mass), and MO/POE ( $1 \% / 99 \%$ by mass)) were attempted in order to check for sufficient fluorescence intensity. All of the mixtures fluoresced well. Consequently, the mixture with the least amount of MO was selected for this study. With the addition of $1 \%$ mass MO, the intensity of the mixture (MO/POE (1\%/99 \% by mass)) was more than ten times larger than that of the pure POE.

Figure 11 shows the analysis of the emission and excitation spectra of $\mathrm{MO} / \mathrm{POE}$ ( $1 \% / 99 \%$ by mass) in a cuvette. The test sample was placed directly in the sample chamber of the right angle spectrofluorometer. The excitation wavelength that produced the maximum fluorescence emission was iteratively found by scanning through both the excitation and the emission wavelengths. The excitation and the emission wavelengths for the lubricant that produced the largest intensities were located at $320 \mathrm{~nm}$ and $380 \mathrm{~nm}$, respectively.

The emission and excitation wavelength measurements were verified with a mercury standard and a "crossover-peak" from the excitation. The emission wavelength measurement obtained from the spectrofluorometer was checked against a mercury vapor light. Figure 12 and Table 2 show a comparison of the published values of the peak wavelengths for mercury (Reader et al., 1980) to those obtained from the spectrofluorometer. The absolute difference between the measured and published wavelengths was approximately $\pm 2.5 \mathrm{~nm}$, which was the width of the slits in the spectrofluorometer.

The excitation wavelength measurement obtained from the spectrofluorometer was checked with a "crossover peak" from the excitation. In other words, the excitation monochromator was set to a specific wavelength with no specimen in the sample chamber. Under these conditions, the emission intensity should peak at the excitation wavelength. The wavelength of the emission peaked at the excitation wavelength to within the resolution of the digital display $( \pm 1 \mathrm{~nm})$ for the wavelengths that were tested.

\section{Fluorescence Setup}

Figure 13 shows a schematic of the apparatus that was used to record the presence of the lubricant in the refrigerant/lubricant mixture as it passed through a quartz tube at the exit 
of the two-phase flow heat transfer test section. An aluminum chamber was designed to enclose the quart tube, hold the excitation source, and support the digital camera. The camera was orientated perpendicular to the axis of the incident light to minimize interference from the excitation source. The enclosure was fitted at the bottom and at the front side to accommodate the $380 \mathrm{~nm}$ and the $320 \mathrm{~nm}$ interference filters, which correspond to the optimal excitation and emission intensities as shown in Fig. 13. The inside of the box was painted black to reduce reflection from the inner surfaces. The base of the box was designed to ensure the light source, a long-wave ultra violet lamp, would fit into the casing. The enclosure was carefully fitted over the quartz tube to prevent light leakage from the enclosure to the room.

Observations were made of both the fluorescent and the excitation light incident to an annular flow of R410A/POE in the quartz tube at a wavelength of approximately $380 \mathrm{~nm}$. By design, only the fluorescent light induced by the POE should pass to the camera. In order to have enough light to excite the camera, observations were made with the emission filter removed from the box. As a result, it was impossible to distinguish between the fluorescent and the excitation light. Future improvements to the design of the setup would possibly include a greater wattage excitation lamp and/or wider bandpass interference filters to permit more light to the camera, and/or a lens to focus the light source into the test tube.

\section{CONCLUSIONS}

Local convective boiling measurements for lubricant-free R410A and a R410A/POE lubricant mixture (99.6/0.4) in a fluid heated micro-fin tube were presented. The measured convective boiling Nusselt numbers were compared with an existing correlation. Approximately $71 \%$ of the measured, lubricant-free, data fall within $\pm 20 \%$ of the predicted data. Similarly, 83 \% of the measured R410A/POE Nusselt numbers were predicted to within $\pm 20 \%$.

In general, the measured boiling heat-transfer coefficients exhibited little variation with increasing qualities. An average degradation of $6.7 \%$ was observed in the heat transfer coefficient of the R410A/POE mixture when compared with the lubricant-free R410A. The relative heat transfer of the R410A/POE mixture was between $-20 \%$ and $+42 \%$ of that of the lubricant-free R410A.

A fluorescence setup was designed to observe fluorescence for identification of and location of the lubricant in the convective flow. The optimum emission and excitation wavelengths were identified using the spectrofluorometer. A source lamp with a greater intensity, a lens to focus the source onto the tube, and interference filters with wider band widths would all likely improve the observation of the fluorescence intensity.

\section{ACKNOWLEDGEMENTS}

This work was funded by NIST. The authors thank the following NIST personnel for their constructive criticism of the first draft of the manuscript: Dr. P. Domanski, Dr. W. V. Payne, and Dr. M. Kim. Thanks also go to Wolverine Tube, Inc., for supplying the Turbo-A, micro-fin tube for the test section. The RL68H (POE) lubricant that was 
donated by Dr. S. Randles of ICI is much appreciated. The mineral oil that was mixed with the POE to obtain a significant fluorescence (York-C) was donated by Mr. K.

Starner and Dr. M. Naduvath of York and is much appreciated. 


\section{NOMENCLATURE}

$a \quad$ fourth degree polynomial in $w_{\mathrm{l}}$, eq. (2) (K)

$A_{\mathrm{c}} \quad$ cross sectional flow area inside tube $\left(\mathrm{m}^{2}\right)$

$A_{\mathrm{n}} \quad$ coefficients given in eq. (3)

$A_{\mathrm{i}} \quad$ actual inner surface area of tube $\left(\mathrm{m}^{2}\right)$

$A_{\mathrm{r}} \quad$ ratio of actual inner surface area of micro-fin tube to that of a smooth tube of inner diameter $\mathrm{D}_{\mathrm{r}}$

$b \quad$ fourth degree polynomial in $w_{\mathrm{l}}$, eq. (2)

$B_{\mathrm{n}} \quad$ coefficients given in eq. (4)

Bo local boiling number, $\mathrm{q}$ "/ $\mathrm{G}_{\mathrm{r}} \mathrm{i}_{\mathrm{fg}}$

$C_{\mathrm{p}} \quad$ specific heat $(\mathrm{J} / \mathrm{kg} \cdot \mathrm{K})$

$C_{\mathrm{n}} \quad$ coefficients given in eq. 8

$D$ tube diameter (m)

$D_{\mathrm{e}} \quad$ equivalent inner diameter of smooth tube, $(4 \mathrm{Ac} / \Pi)^{0.5}(\mathrm{~m})$

$D_{\mathrm{h}} \quad$ hydraulic diameter of micro-fin tube (m)

$e \quad$ fin height (m)

$E_{\mathrm{h}} \quad$ heat-transfer enhancement ratio

$G \quad$ total mass velocity $\left(\mathrm{kg} / \mathrm{m}^{2} \cdot \mathrm{s}\right)$

$h_{2 \phi} \quad$ local two-phase heat-transfer coefficient $\left(\mathrm{W} / \mathrm{m}^{2} \cdot \mathrm{K}\right)$

$i_{\text {fg }} \quad$ latent heat of vaporization $(\mathrm{J} / \mathrm{kg})$

$k \quad$ refrigerant thermal conductivity $(\mathrm{W} / \mathrm{m} \cdot \mathrm{K})$

$L \quad$ tube length (m)

$\mathrm{Nu} \quad$ local Nusselt number based on $\mathrm{D}_{\mathrm{h}}$

$N_{\mathrm{f}} \quad$ number of fins

$m$ mass flow rate $(\mathrm{kg} / \mathrm{s})$

$M_{\mathrm{r}} \quad$ molar mass $(\mathrm{g} / \mathrm{mol})$

$p \quad$ wetted perimeter (m)

$P \quad$ local fluid pressure $(\mathrm{Pa})$

$\operatorname{Pr} \quad$ liquid refrigerant Prandtl number

q” local heat flux based on $\mathrm{A}_{\mathrm{i}}\left(\mathrm{W} / \mathrm{m}^{2}\right)$

Re all liquid, refrigerant Reynolds number based on $D_{h}$

$s \quad$ spacing between the fins

$S \quad$ perimeter of one fin and channel (m)

$S_{\mathrm{v}} \quad$ non-dimensional refrigerant specific volume

$t_{\mathrm{b}} \quad$ thickness of the fin at its base (m)

$t_{\mathrm{w}} \quad$ thickness of the tube wall (m)

$T$ temperature (K)

$T_{\mathrm{b}} \quad$ bubble point temperature of mixture (K)

$T_{\mathrm{d}} \quad$ dew point temperature of mixture $(\mathrm{K})$

$U$ expanded relative uncertainty

$w \quad$ lubricant mass fraction

$x_{\mathrm{q}} \quad$ thermodynamic mass quality

$\mathrm{z} \quad$ axial distance $(\mathrm{m})$ 


\section{Subscripts}

b bulk condition, fin base, bubble point

c critical condition

d degradation, dew point

f water

i inlet, inner

l local

LV least volatile

$\mathrm{m}$ measured

MV most volatile

p plain or smooth tube, predicted

$\mathrm{r}$ refrigerant

s saturated state

w heat transfer surface

v vapor 


\section{REFERENCES}

Baustian, J. J., Pate, M. B., and Bergles, A. E., 1988a, "Measuring the Concentration of a Flowing Oil-Refrigerant Mixture with an Acoustic Velocity Sensor," ASHRAE Trans., Vol. 94, No. 2, pp. 602-615.

Baustian, J. J., Pate, M. B., and Bergles, A. E., 1988b, "Measuring the Concentration of a Flowing Oil-Refrigerant Mixture with a Bypass Vicometer," ASHRAE Trans., Vol. 94, No. 2, pp. 588-594.

Baustian, J. J., Pate, M. B., and Bergles, A. E., 1988c, "Measuring the Concentration of a Flowing Oil-Refrigerant Mixture with a Vibrating U-Tube Densimeter," ASHRAE Trans., Vol. 94, No. 2, pp. 571-587.

Bayani, A., Thome, J. R., and D. Favrat, 1995, "Online Measurement of Oil Concentrations of R-134a/Oil Mixtures with a Density Flowmeter," $\underline{\text { HVAC\&R Research, }}$ Vol. 1, No. 3, pp. 232-241.

Cooper, M.G., 1984, Saturation Nucleate Pool Boiling- A Simple Correlation Vol. 86, Department of Engineering Science, Oxford University, England, pp. 785-793.

Cremaschi, L., Hwang, Y., and Radermacher, R., 2005, "Experimental Investigation of Oil Retention in Air Conditioning Systems,” Int. J. Refrig., Vol. 28, pp. 1018-1028.

Kattan, N., Favret, D., and Thome, J. R., 1995, "R-502 and two near-azeotropic alternatives: Part 1 - In tube flow-boiling tests,” ASHRAE Transactions, Vol. 101, Pt. 1, pp. $491-508$.

Kedzierski, M. A., Bruno, T. J., and O’Neil, M. B., 1998,”A New Insitu Technique for Measuring the Concentration of Lubricant on a Boiling Heat Transfer Surface,” NISTIR 6110, U.S. Department of Commerce, Washington, D.C.

Kedzierski, M. A., and Goncalves, J. M., 1999, "Horizontal Convective Condensation of Alternative Refrigerants Within a Micro-Fin Tube,” Journal of Enhanced Heat Transfer, Vol. 6, No. 2-4, pp. 161-178.

Hamilton, L. J., Kedzierski, M. A., and Kaul, M. P., 2005, “Horizontal Convective Boiling of Refrigerants and Refrigerant Mixtures within a Micro-Fin Tube,” NISTIR 7243, U.S. Department of Commerce, Washington, D.C.

Kim, M., and Shin, J., 2005, "Evaporating Heat Transfer of R22 and R410A in Horizontal Smooth and Microfin Tubes,” Int. J. Refrig., Vol. 28, pp. 940-948.

Lemmon, E. W., Huber, M. L, and McLinden, M. O., 2006, NIST reference fluid thermodynamic and transport properties-REFPROP. NIST standard reference database 23-Version 7.1. 
Lottin, O., Guillemet, P., and Lebreton, J.-M., 2003, "Effects of Synthetic Oil in a Compression Refrigeration System Using R410A. Part II: Quality of Heat Transfer and Pressure Losses Within the Heat Exchangers,” Int. J. Refrig., Vol. 28, pp. 1018-1028.

Meyer, J. J., and Saiz Jabardo, J. M., 1994, "An Ultrasonic Device for Measuring the Oil Concentration in Flowing Liquid Refrigerant," Int. J. of Refrigeration, Vol. 17, No. 7, pp. 481-486.

Navarro de Andrade, E., Skowron, E., Goldschmidt, V. W., and Groll, E. A., 1999, "Oil Concentration in liquid refrigerants: in situ measurement," Int. J. of Refrigeration, Vol. 22, No. 6, pp. 499-508.

Reader, J, Corliss, C. H., Wiese, W. L., and Martin, G. A., 1980, "Wavelengths and Transition Probabilities of Atoms and Atomic Ions", NSRDS-National Bureau of Standards \#68, U.S. Department of Commerce, Washington.

Suzuki, S., Fujisawa, Y., Nakazawa, S., and Matsuoka, M., 1993, "Measuring Method of Oil Circulation Ratio Using Light Absorption," ASHRAE Trans., Vol. 99, No. 1, pp. 413421.

Thome, J., R., 1995, “Comprehensive Thermodynamic Approach to Modeling Refrigerant-Lubricating Oil Mixtures,” HVAC\&R Research, Vol. 1, No. 2, pp. 110-125.

Webb, R. L., 1994, Principles of Enhanced Heat Transfer, Wiley Interscience. 
Table 1 Median estimated $95 \%$ relative expanded uncertainties and range for measurements

\begin{tabular}{||c|c|c|c||}
\hline Parameter & Minimum & Maximum & $\mathrm{U} \%$ \\
\hline$G_{\mathrm{r}}\left[\mathrm{kg} / \mathrm{m}^{2} \cdot \mathrm{s}\right]$ & 57 & 552 & 2.0 \\
\hline$T_{\mathrm{r}}[\mathrm{K}]$ & 293.0 & 323.0 & $0.1(0.3 \mathrm{~K})$ \\
\hline$P[\mathrm{kPa}]$ & 600 & 2000 & 1.5 \\
\hline$T_{\mathrm{W}}[\mathrm{K}]$ & 288.0 & 318.0 & $0.1(0.25 \mathrm{~K})$ \\
\hline$\dot{m}_{f}[\mathrm{~kg} / \mathrm{s}]$ & 0.0150 & 0.0450 & 2.0 \\
\hline$T_{\mathrm{f}}[\mathrm{K}]$ & 278.0 & 313.0 & 0.1 \\
\hline$P_{\mathrm{f}}[\mathrm{kPa}]$ & 200 & 110 & 1.0 \\
\hline$q^{\prime \prime}\left[\mathrm{kW} / \mathrm{m}^{2}\right]$ & 1.5 & 43.8 & 5.1 \\
\hline $\mathrm{d} T_{\mathrm{f}} / \mathrm{dz}[\mathrm{K} / \mathrm{m}]$ & 0.009 & 0.45 & 5.2 \\
\hline $\mathrm{Nu}$ & 78 & 410 & 16.4 \\
\hline $\mathrm{Re}$ & 5300 & 16500 & 4.0 \\
\hline $\mathrm{x}_{\mathrm{q}}$ & 0.001 & .72 & 8.0 \\
\hline$\Delta T_{\mathrm{s}}[\mathrm{K}]$ & 0.8 & 6.0 & $15.2(0.44 \mathrm{~K})$ \\
\hline \hline
\end{tabular}


Table 2 Calibration check of spectrofluorometer against Mercury lamp

\begin{tabular}{|c|c|c|c|}
\hline $\begin{array}{l}\text { Published* } \\
\text { Wavelength (nm) }\end{array}$ & $\begin{array}{c}\text { Measured Wavelength } \\
(\mathrm{nm})\end{array}$ & $\begin{array}{c}\text { Absolute Difference } \\
(\%)\end{array}$ & $\begin{array}{c}\text { Relative Difference } \\
(\%)\end{array}$ \\
\hline 312.567 & 310 & 2.567 & 0.8 \\
\hline 365.015 & 362 & 3.015 & 0.83 \\
\hline 404.656 & 402 & 2.656 & 0.66 \\
\hline 435.833 & 434 & 1.833 & 0.42 \\
\hline 546.074 & 545 & 1.074 & 0.2 \\
\hline 576.96 & 578 & -1.04 & -0.18 \\
\hline
\end{tabular}

* Reader et al. (1980) 


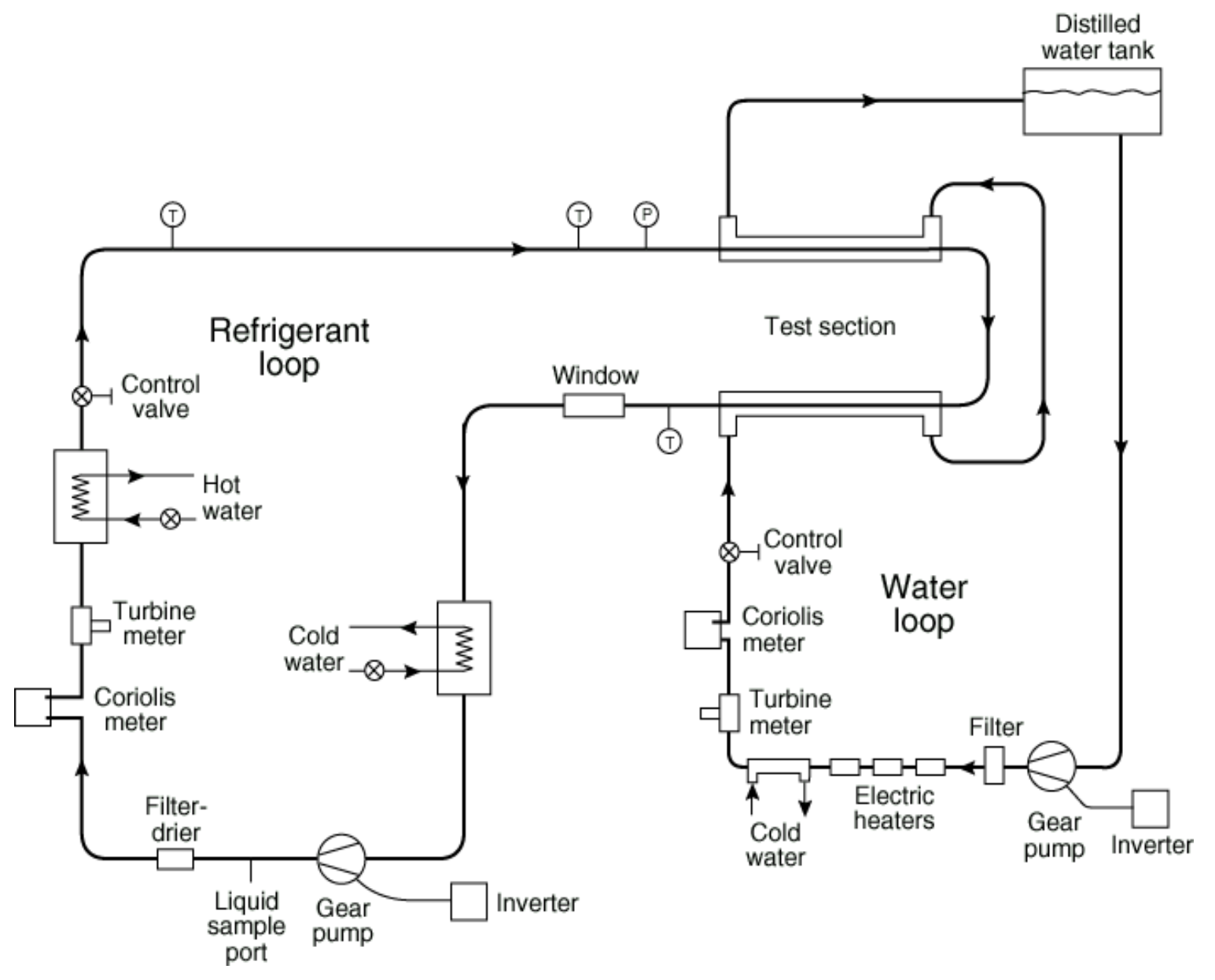

Fig. 1 Schematic of test rig 


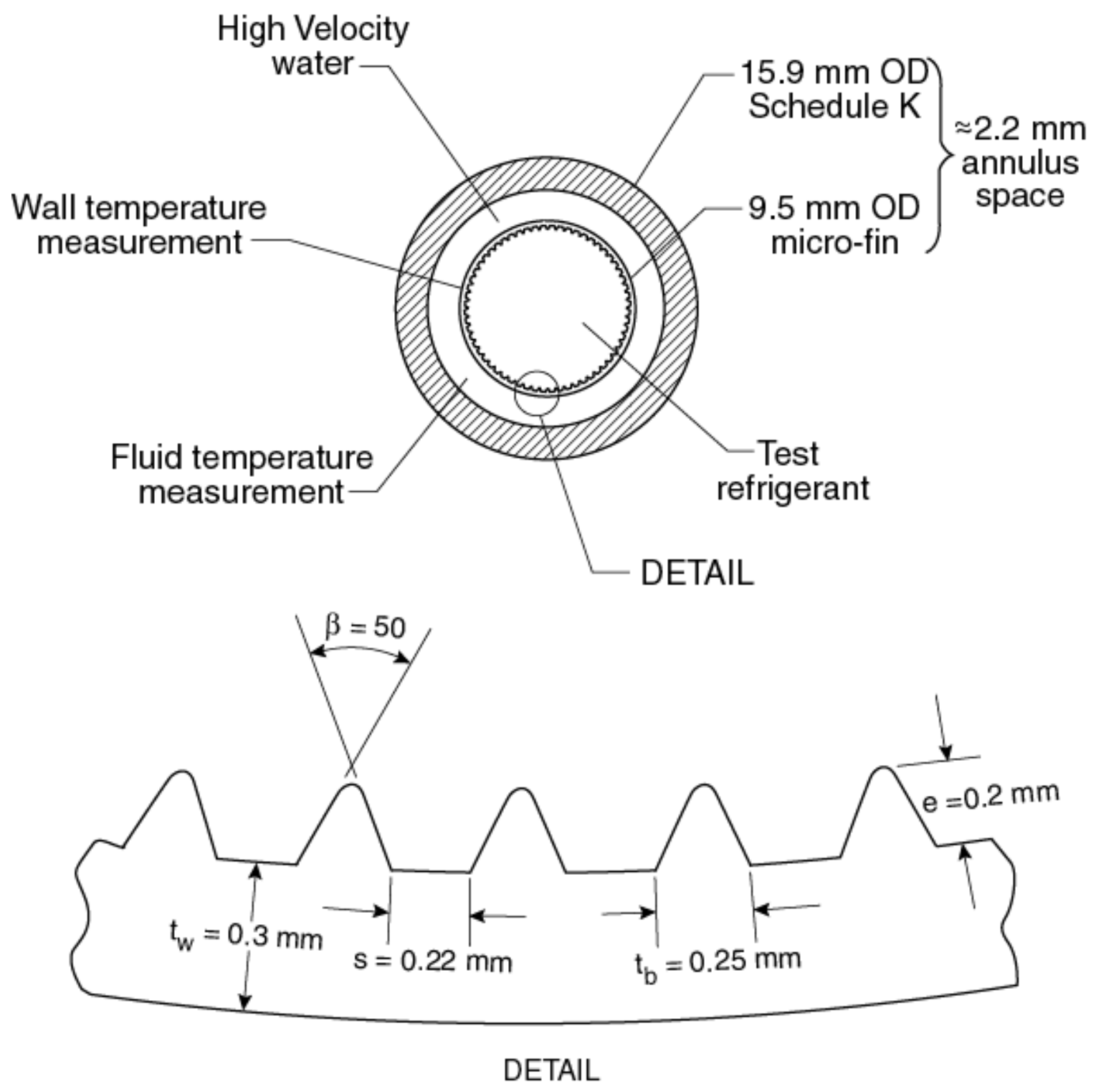

Fig. 2 Cross section of test section 


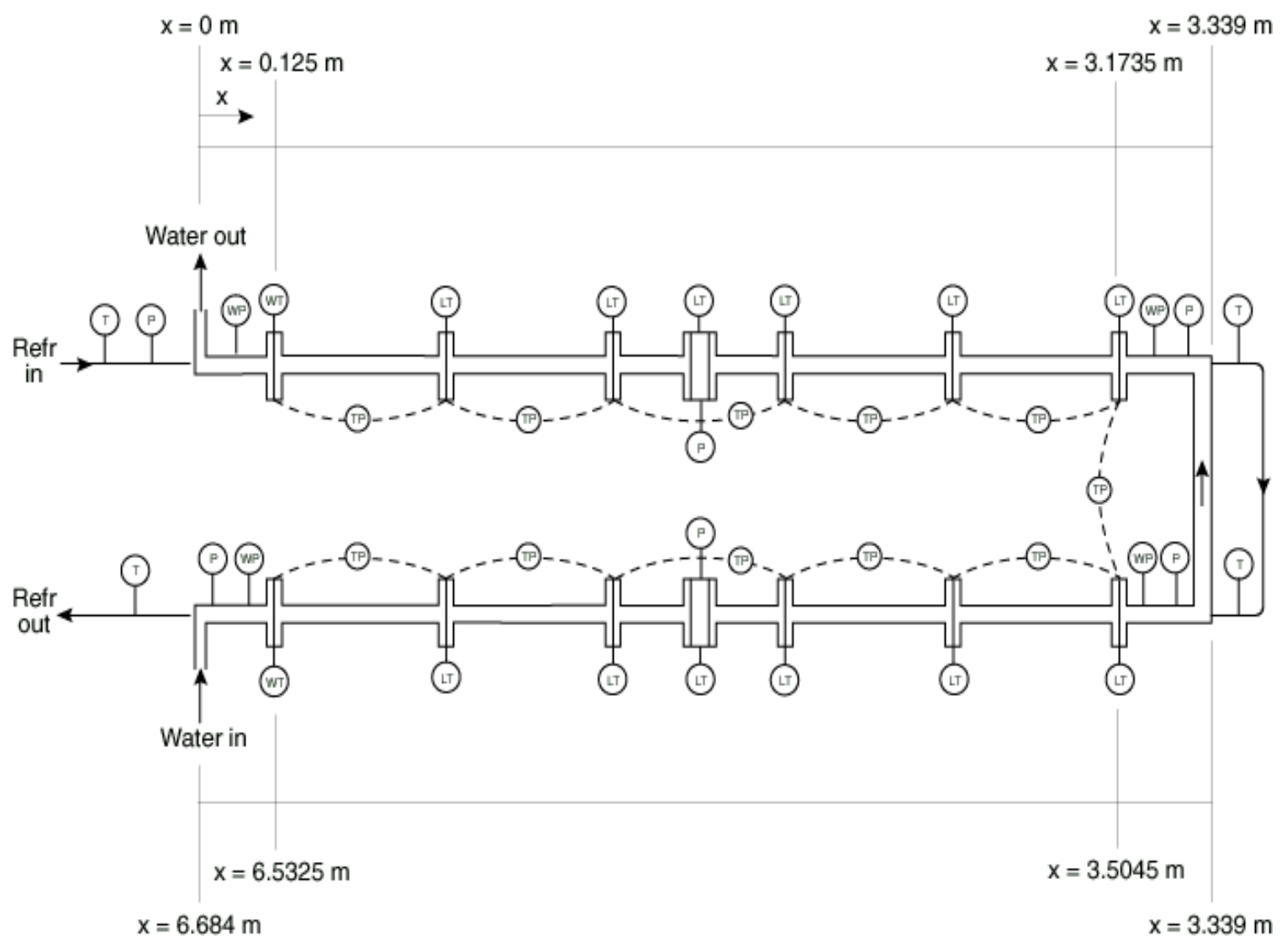

Fig. 3 Test section detail 


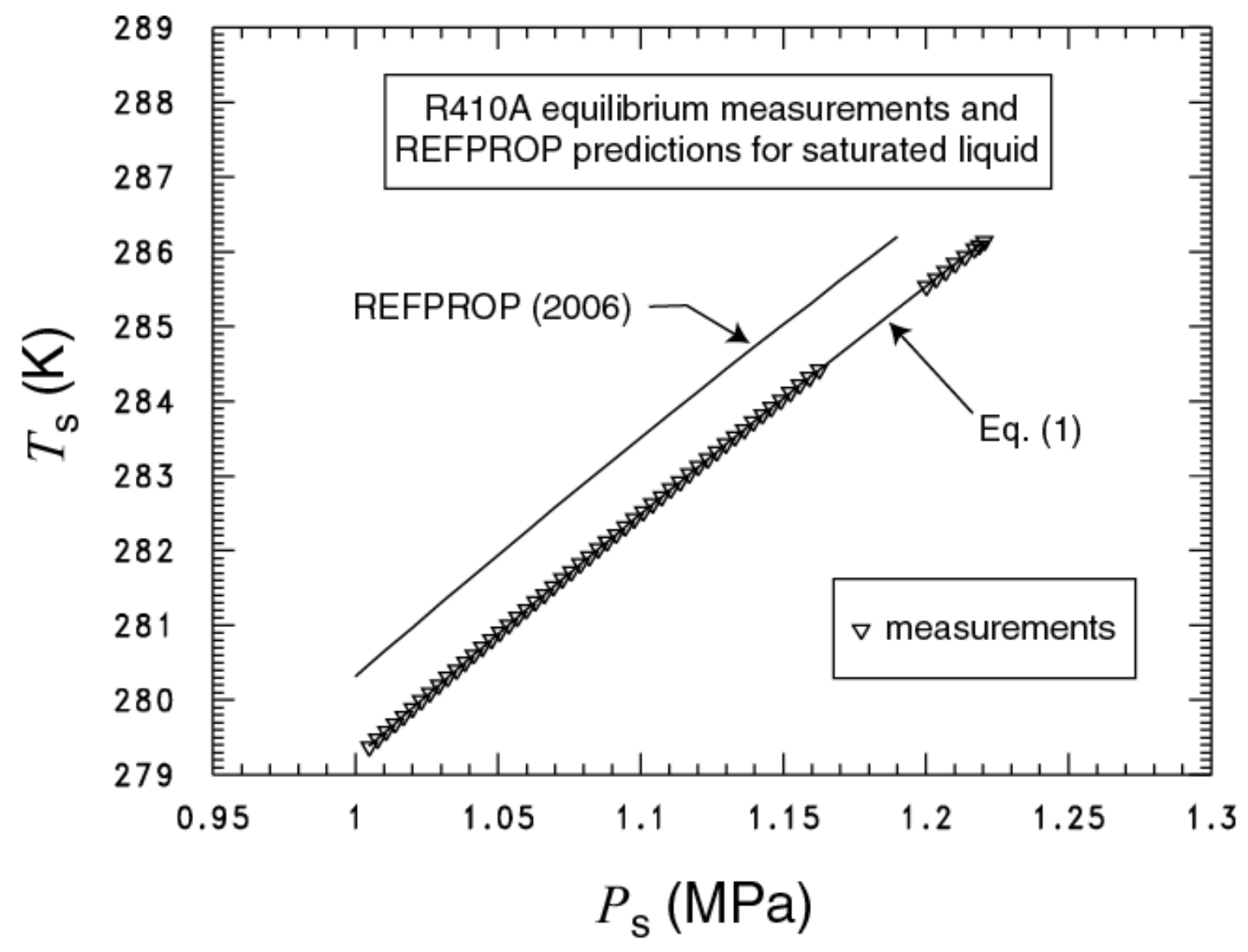

Fig. 4 Comparison of measurements with REFPROP 7.1 (2006) 


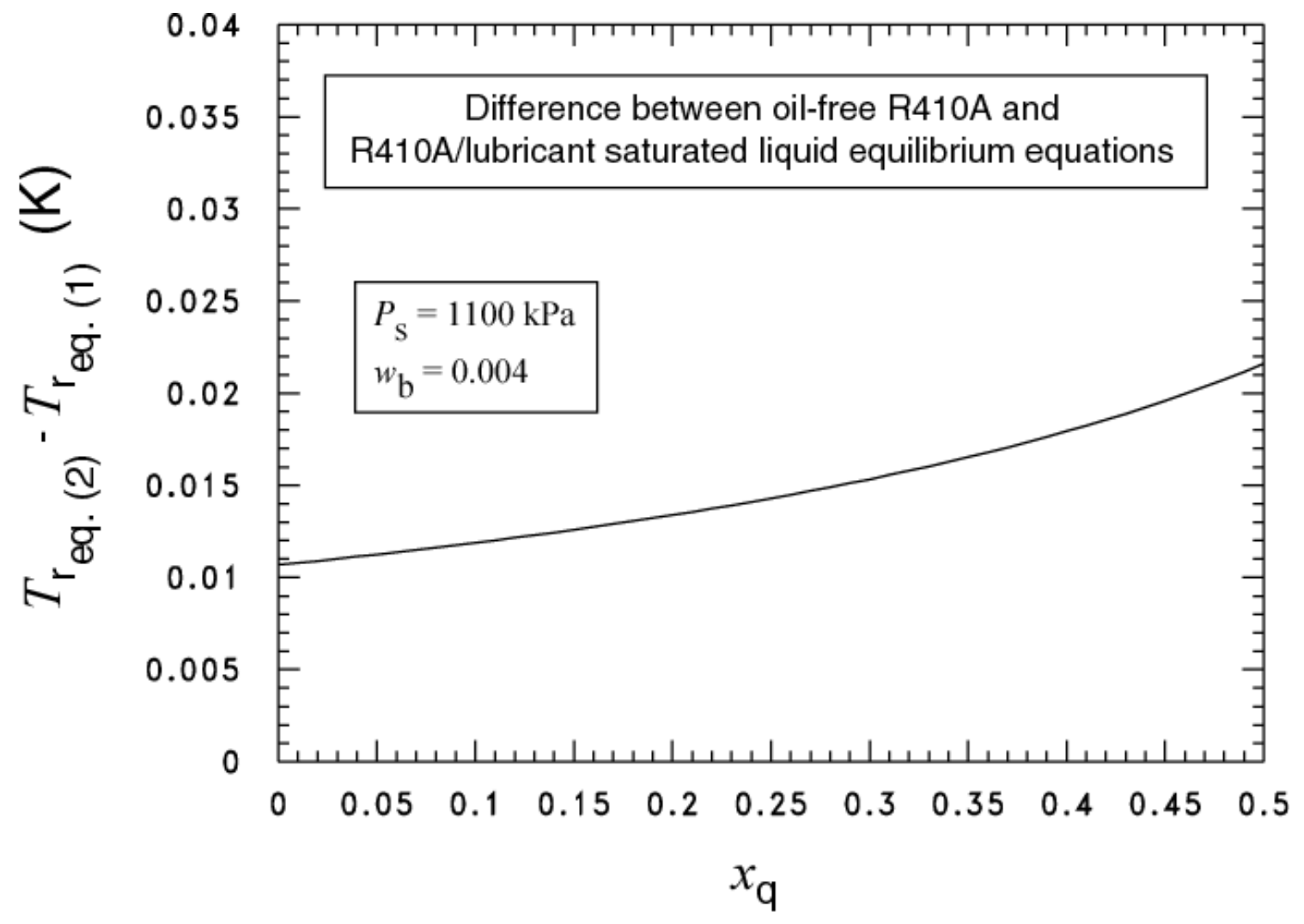

Fig. 5 Difference between oil-free R410A and R410A/POE saturated liquid equilibrium equations 


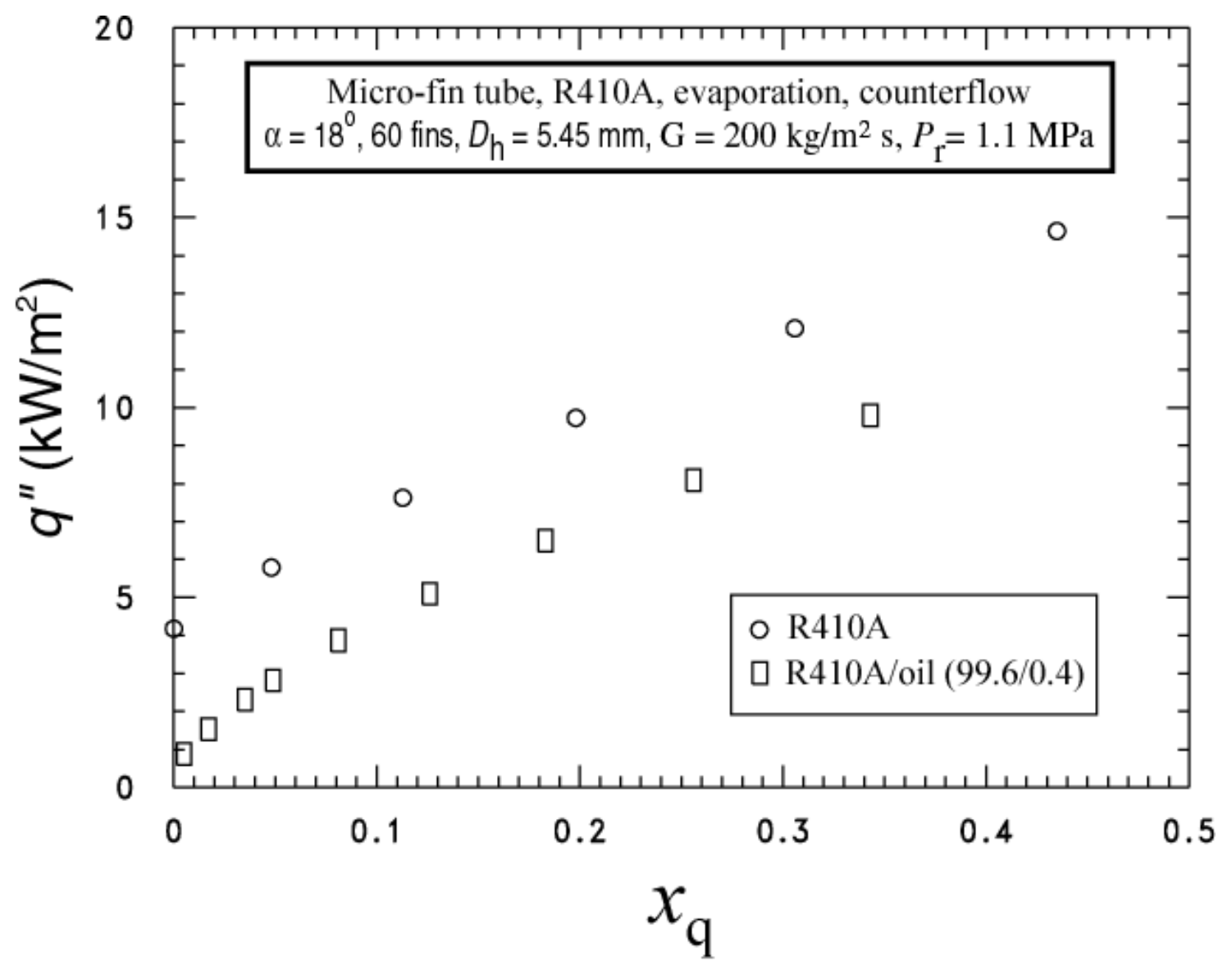

Fig. 6 Heat flux distribution for pure R410A and R410A/POE mixture 


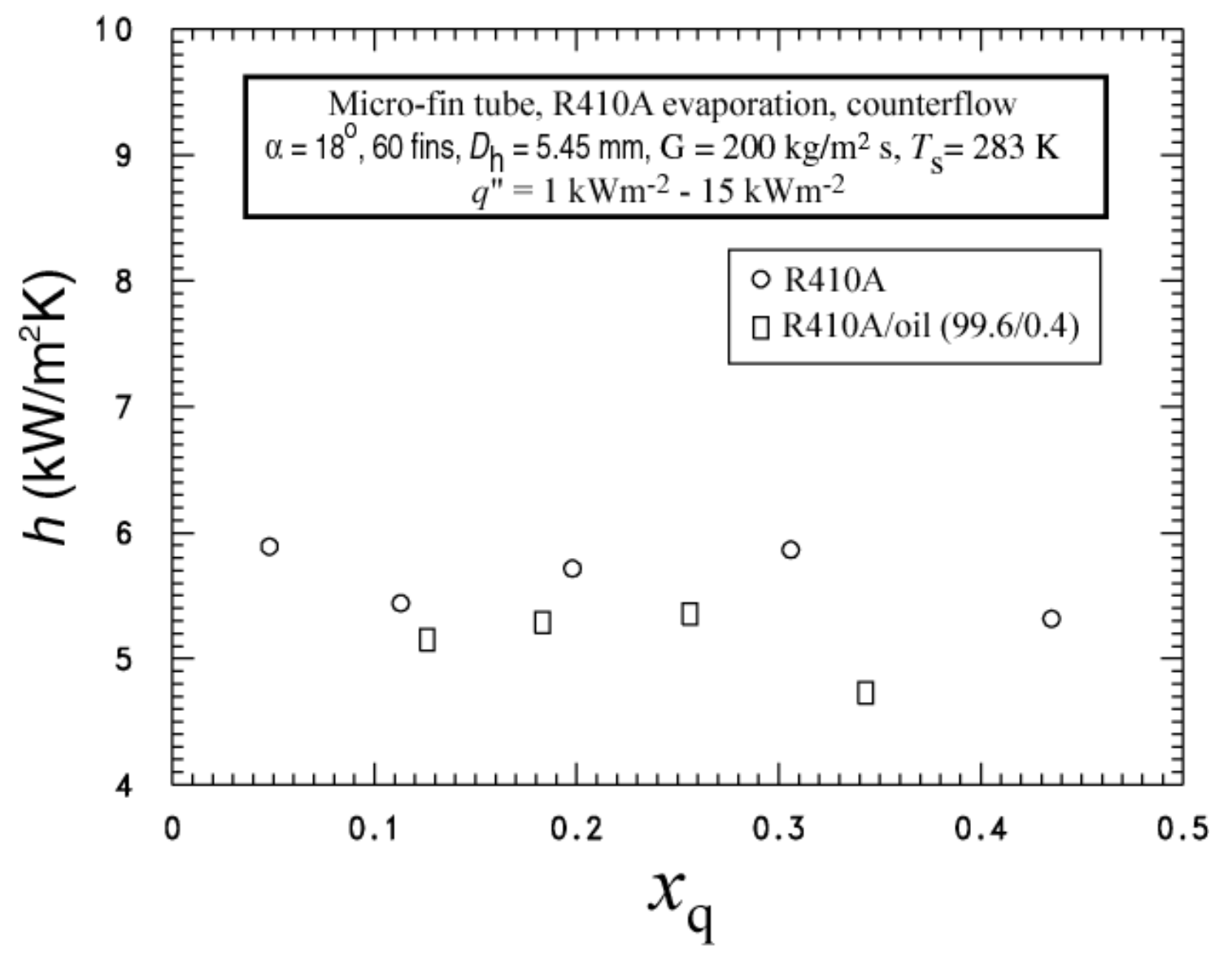

Fig. 7 Comparison of the heat transfer coefficient for pure R410A and R410A/POE mixture 


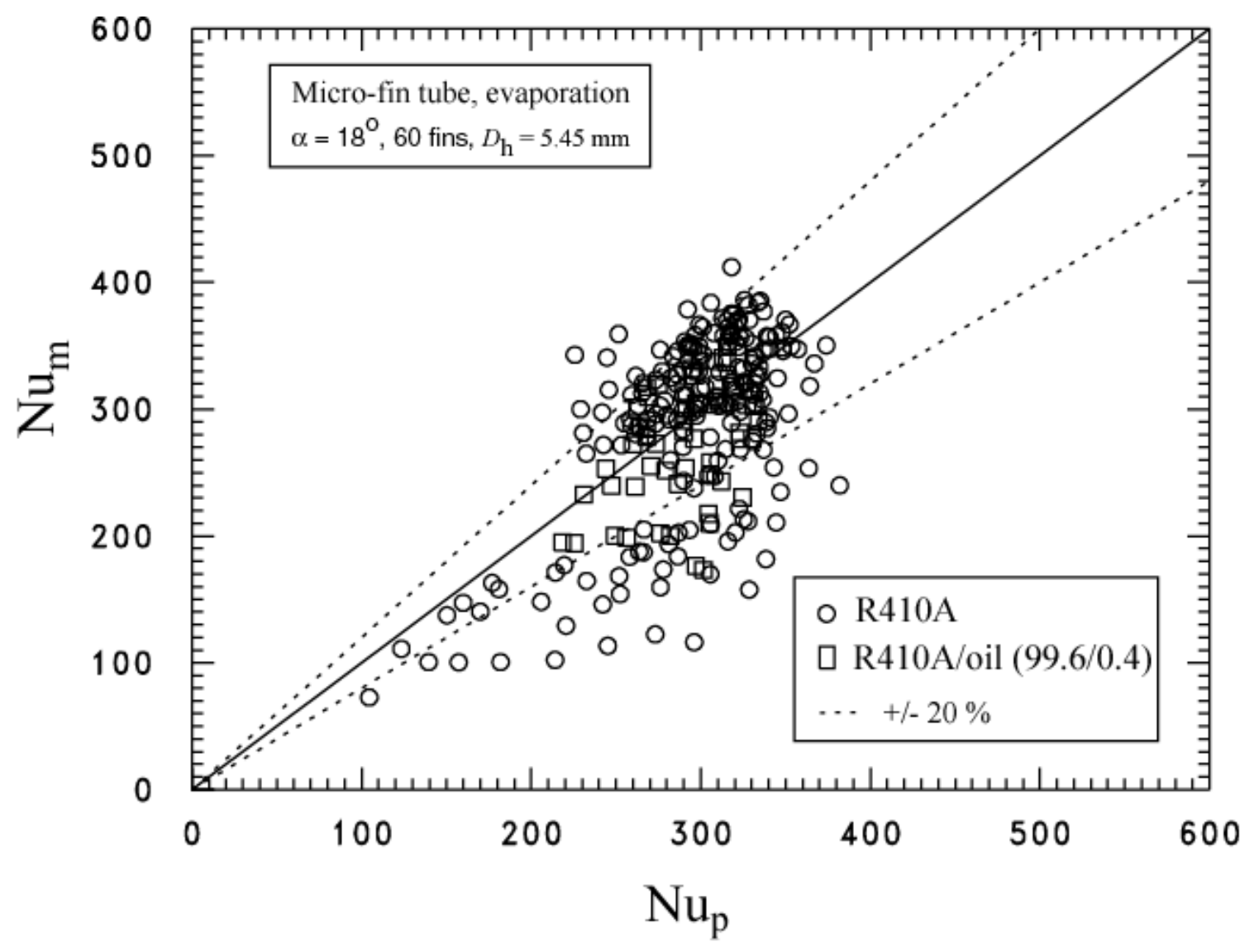

Fig. 8 Comparison of counterflow data with existing correlation 


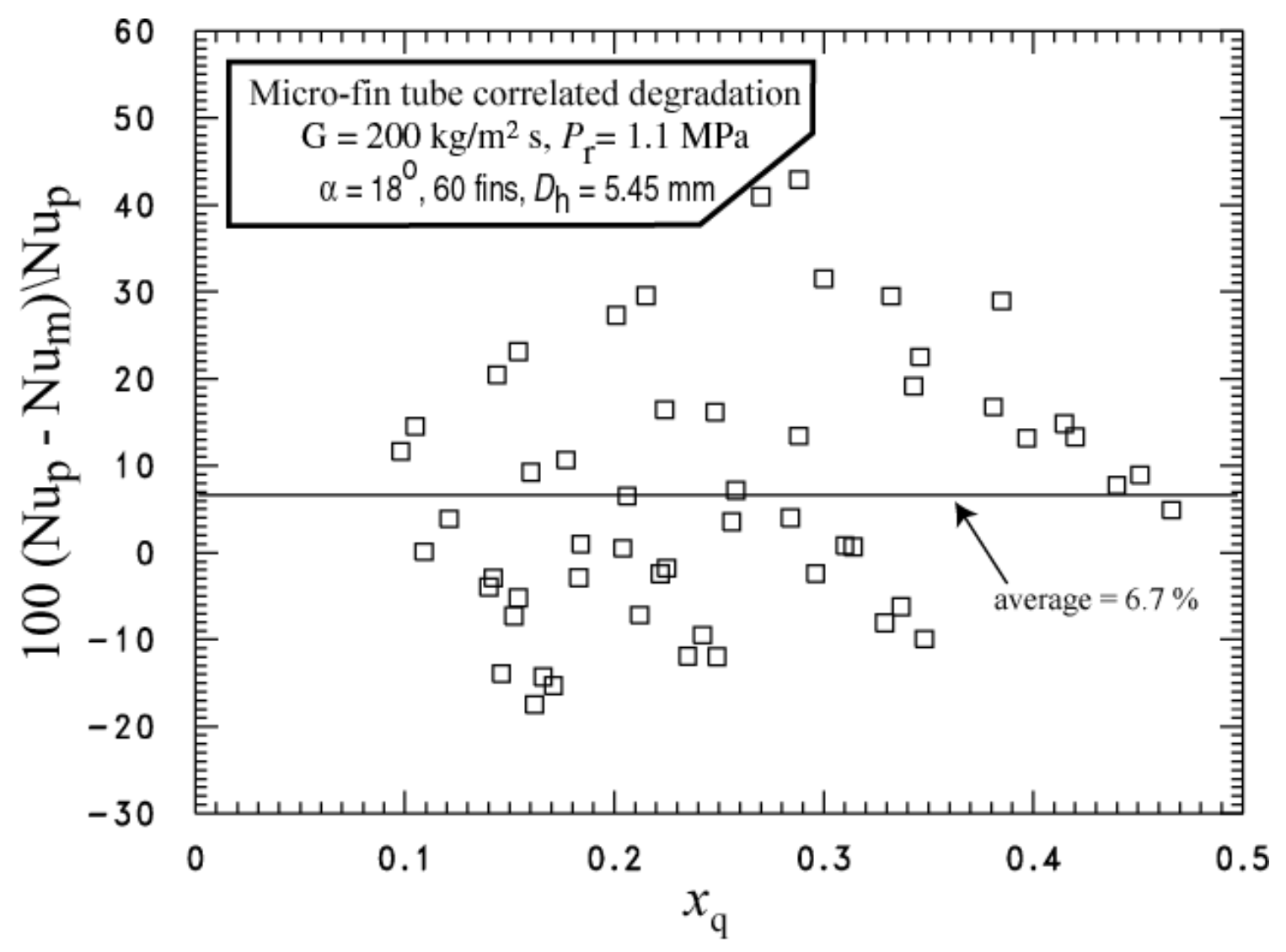

Fig. 9 Apparent heat transfer degradation due to oil 


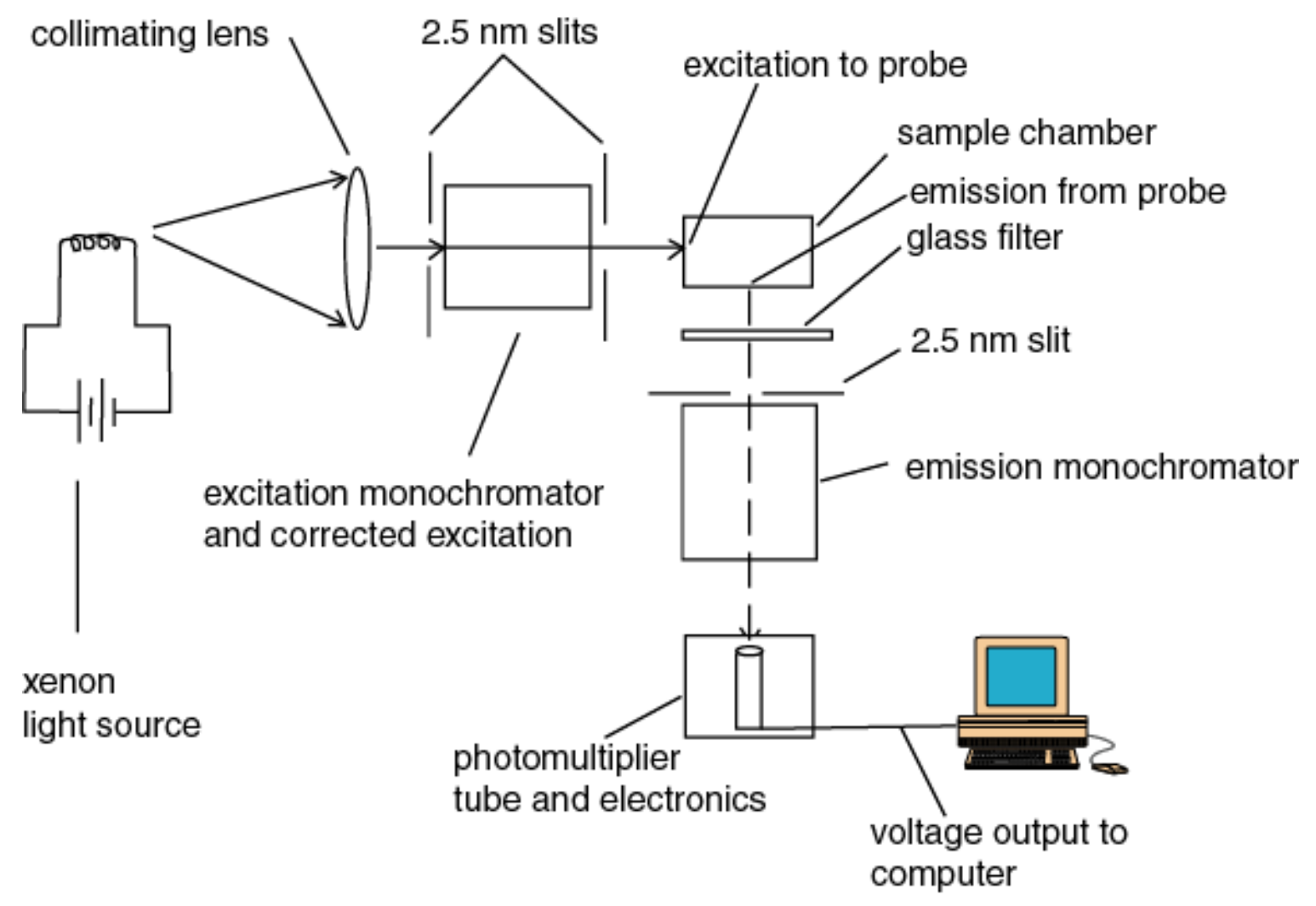

Fig. 10 Schematic of right angle spectrofluorometer 



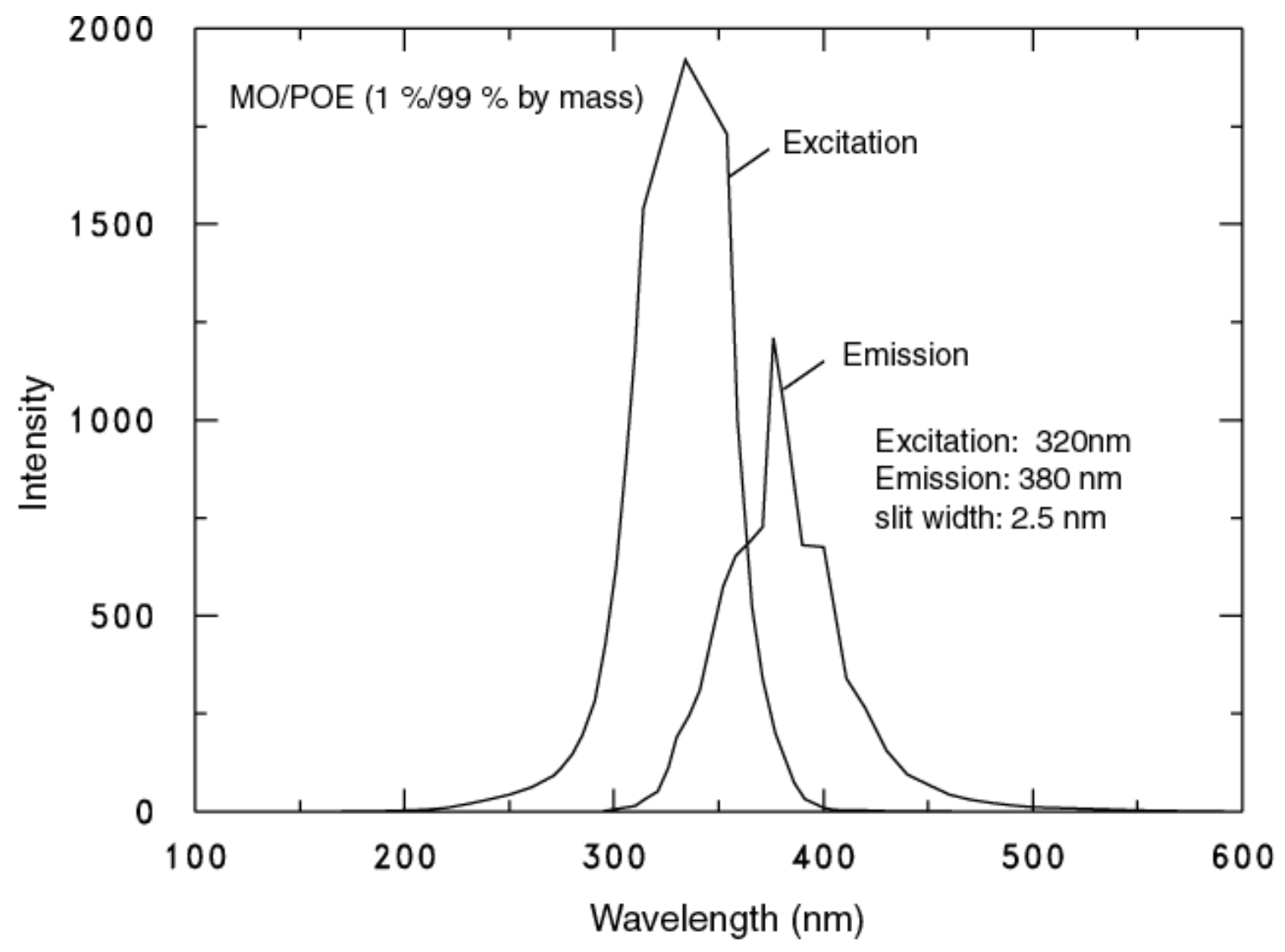

Fig. 11 Fluorescence spectra of R410A/POE mixture 


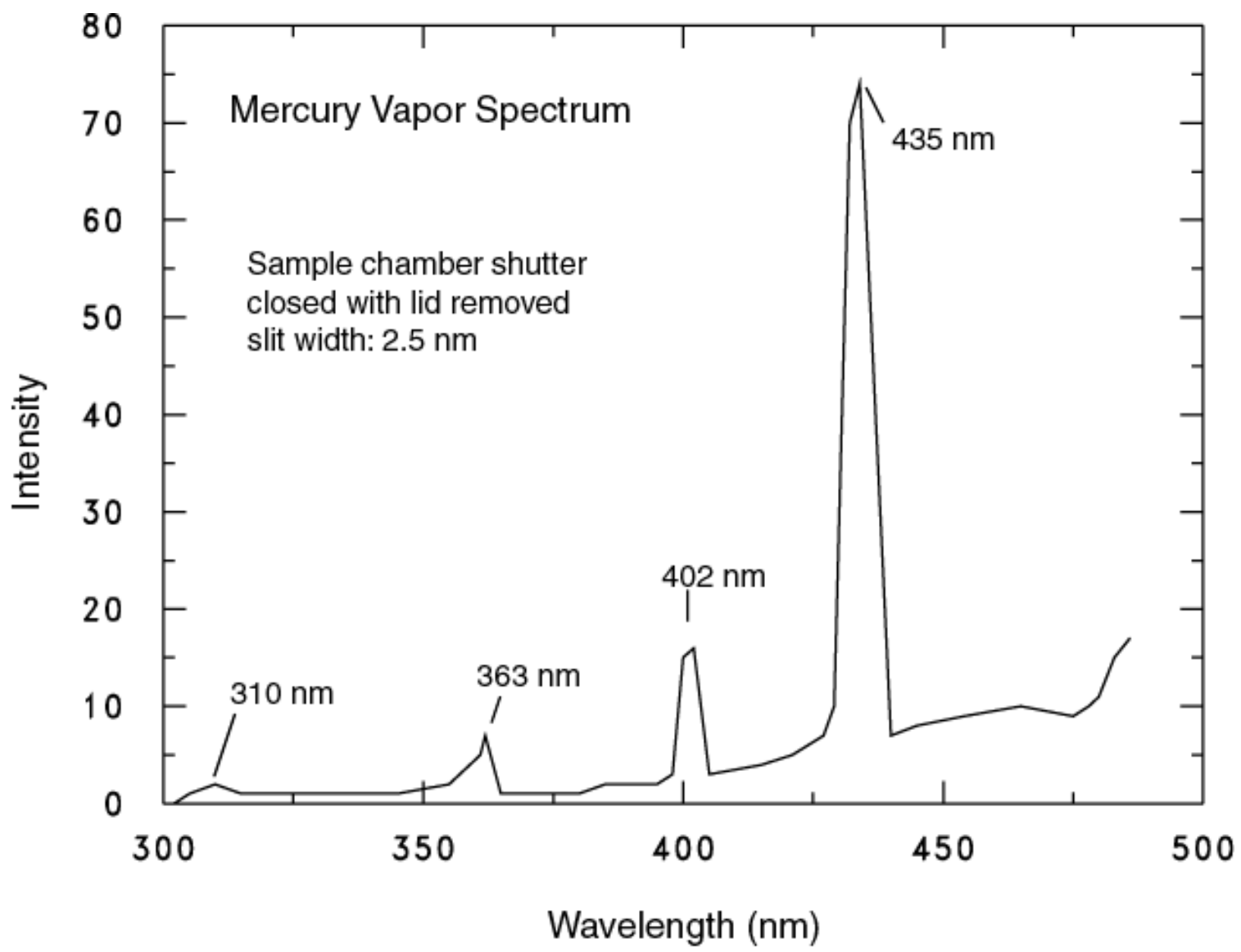

Fig. 12 Mercury Spectra $($ Excitation $=300$ nm) 


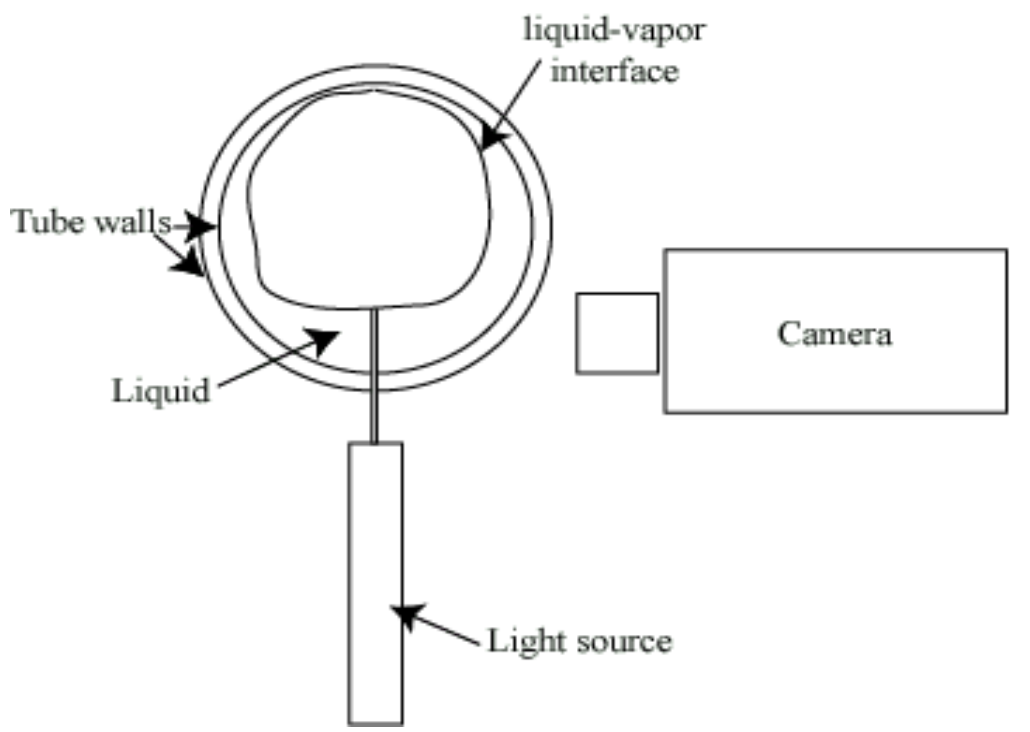

Fig. 13 Lubricant concentration observation test section 